\title{
Telangiectatic cutaneous metastasis from breast carcinoma
}

\section{Soukaina Maghfour ${ }^{1}$, Yosra Soua ${ }^{1}$, Nouha Abdejlil' ${ }^{2}$ Nadia Nabli', Mouna Korbi', Hichem Belhadjali', Monia Youssef', Jameleddine Zili'}

${ }^{1}$ Dermatology Department, Fattouma Bourguiba University Hospital, Monastir-Tunisia, ${ }^{2}$ Anatomopathology Department, Fattouma Bourguiba University Hospital, Monastir-Tunisia

Corresponding author: Dr. Soukaina Maghfour, E-mail: soukou@outlook.fr

\begin{abstract}
Cutaneous metastasis from breast cancer has varied clinical presentations. Herein, we present the case of a middleaged female with a large erythematous patch and an itchy bluish-red papular eruption on the left side of the breast. The patient had a history of ductal breast carcinoma at age 40. Histology from one of the red papules revealed an atrophic epidermis and emboli of carcinomatous cells in the dermal and subcutaneous blood vessels. The morphology of the tumor cells was similar to that of the primary ductal carcinoma of the breast. The diagnosis of telangiectatic metastatic breast cancer was reached.
\end{abstract}

Key words: Breast carcinoma; Intravascular tumor emboli; Telangiectatic carcinoma; Metastatic carcinoma;

Ductal carcinoma

\section{INTRODUCTION}

Breast cancer is the most common cause of cutaneous metastasis in women. The clinical presentations of cutaneous metastasis vary, but infiltrative nodules are the most common feature. Telangiectatic cutaneous metastasis is rare. Herein, we report a new case of angiokeratoma-like lesions.

\section{CASE REPORT}

A 42-year-old female presented herself to our department with a three-month history of a large erythematous patch and an itchy bluish-red papular eruption on the left side of the breast. Two years before, the patient was successfully treated by mastectomy and axillary lymph node clearance followed by adjuvant chemotherapy and local radiotherapy for infiltrating stage IIIB ductal breast carcinoma. A physical examination revealed an erythematous skin patch associated with multiple bluish-red and violaceous dark papules on the left chest
(Figs. la and lb). The patient had no hepatosplenomegaly or ipsilateral lymphedema. Considering the medical history, cutaneous breast carcinoma metastasis was suspected. A skin biopsy obtained from one of the red papules revealed an atrophic epidermis and emboli of carcinomatous cells in the dermal and subcutaneous blood vessels (Fig. 2a). The morphology of the tumor cells was similar to that of the primary ductal carcinoma of the breast and was of the same histological grade

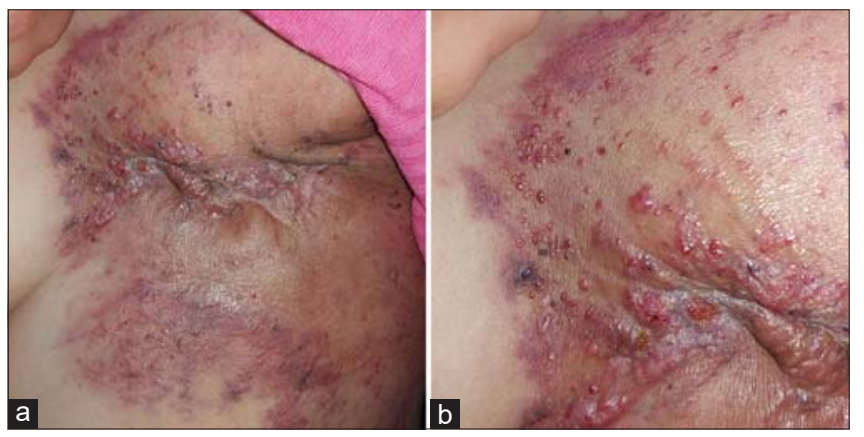

Figure 1: (a) A large erythematous skin patch associated with multiple bluish-red and violaceous dark papules on the left chest. (b) A highpower view of the angiokeratoma-like lesions.

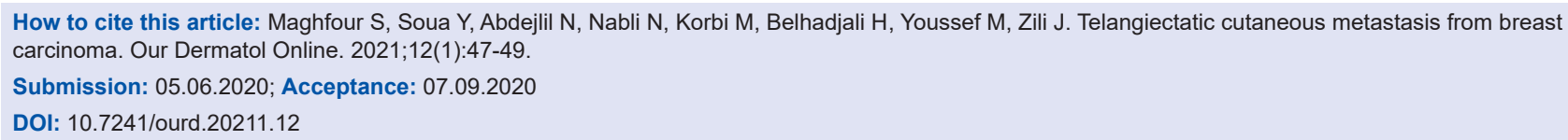




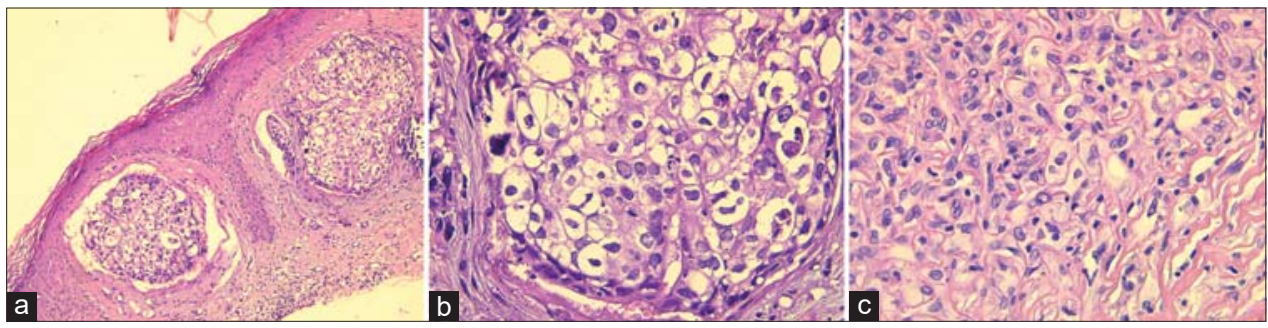

Figure 2: (a) The skin biopsy showing invasive carcinomatous proliferation in the dermis with vascular emboli. (b) Tumor cells showing nuclear atypia with numerous mitoses. (c) A high-power view of foamy histiocytes with abundant, clear cytoplasm. (H\&E; original magnification: (a) 100x, (b-c) $400 x)$.

(Figs. 2a and 2b). The receptor status was unchanged. A further work-up revealed bone metastasis. We referred the patient to a specialized oncology center, where she received sequential treatment with chemotherapy. Unfortunately, the patient passed away while on the chemotherapy, five months after the initial diagnosis of cutaneous metastasis.

\section{DISCUSSION}

Breast carcinoma is the most common tumor that causes cutaneous metastasis after melanoma. In the largest case series published, cutaneous involvement was observed in $23.9 \%$ of patients with breast cancer [1]. The clinical presentations of cutaneous metastasis from breast cancer vary. The lesions are located mostly on the chest and abdominal wall, close to the mastectomy scar. Solitary and multiple papules and nodules are more common. Less frequently, other patterns have been described in the literature [2]. These include telangiectatic carcinoma, erysipeloid carcinoma, carcinoma en cuirasse, neoplastic alopecia, and zosteriform patterns. Telangiectatic carcinoma (TC) manifests itself with prominent telangiectasia and/or pseudovesicles that resemble lymphangioma circumscriptum. It is habitually located on the chest and may appear on the face. In a series of 164 cases with breast cancer, 131 displayed papular and/or nodular lesions, and only 19 had TC [2]. It has also been associated with breast carcinoma, ductal carcinoma of the parotid gland, apocrine carcinoma of the vulva, and carcinoma of the prostate $[3,4]$.

TC occurs due to malignant spread via dermal lymphatics [5]. Cutaneous biopsies reveal infiltration of tumor aggregates predominantly in the dermal lymphatic and blood vessels by neoplastic cells, causing their obstruction [6,7]. Immunohistochemical techniques, such as cytokeratin-7 and cytokeratin-20, contribute to the elucidation of the diagnosis. BRST-2 antigen as well as estrogen and progesterone receptors may also be useful for the diagnosis [8].

Although the prognosis of cutaneous metastasis depends on the type and character of the primary tumor as well as the response to treatment, it is generally considered severe as it accompanies advanced-stage tumors [7]. Cutaneous metastasis from breast cancer is usually evaluated as a severe prognostic factor in which life expectancy is several months, with only a few patients surviving for a year. It is also poorly amenable to treatment [9].

\section{CONCLUSION}

Breast cancer is one of the most common types of cancer that presents skin metastases. Telangiectatic carcinoma with angiokeratoma-like lesions is a rarity in clinical practice and may be easily overlooked. It is important to recognize this rare variant of cutaneous metastasis to avoid delay in accurate diagnosis. Despite having received the recommended treatment, the poor prognosis of our patient was corroborated by the quick progression to death.

\section{Consent}

The examination of the patient was conducted according to the principles of the Declaration of Helsinki.

The authors certify that they have obtained all appropriate patient consent forms, in which the patients have given consent for images and other clinical information to be included in the journal. The patients understand that their names and initials will not be published and due effort will be made to conceal their identity, but that anonymity cannot be guaranteed.

\section{REFERENCES}

1. Lookingbill DP, Spangler N, Helm KF. Cutaneous metastases in patients with metastatic carcinoma: A retrospective study of 4020 patients. J Am Acad Dermatol. 1993;29:228-36. 


\section{www.odermatol.com}

2. Mordenti C, Peris K, Concetta Fargnoli M, Cerroni L, Chimenti S. Acta dermatovenerologica. 2000. Cutaneous metastatic breast carcinoma; p. 9. 2000.

3. Lin JH, Lee JY, Chao SC, Tsao CJ. Telangiectatic metastatic breast carcinoma preceded by en cuirasse metastatic breast carcinoma. $\mathrm{Br}$ J Dermatol. 2004;151:523-4.

4. Reddy S, Bang RH, Contreras ME. Telangiectatic cutaneous metastasis from carcinoma of the prostate. Br J Dermatol. 2007;156:598-600.

5. Marneros AG, Blanco F, Husain S, Silvers DN, Grossman ME. Classification of cutaneous intravascular breast cancer metastases based on immunolabeling for blood and lymph vessels. J Am Acad Dermatol. 2009;60:633-8.

6. Schwartz RA. Cutaneous metastatic disease. J Am Acad Dermatol. 1995;33(2 Pt 1):161 82; quiz 183-6.
7. Hu SC-S, Chen G-S, Lu Y-W, Wu C-S, Lan C-CE. Cutaneous metastases from different internal malignancies: A clinical and prognostic appraisal. J Eur Acad Dermatol Venereol. 2008;22:735-40.

8. Nashan D, Müller ML, Braun-Falco M, Reichenberger S, Szeimies R-M, Bruckner-Tuderman L. Cutaneous metastases of visceral tumours: A review. J Cancer Res Clin Oncol. 2009;135:1-14.

9. Schoenlaub P, Sarraux A, Grosshans E, Heid E, Cribier B. [Survival after cutaneous metastasis: A study of 200 cases]. Ann Dermatol Venereol. 2001;128:1310-5.

Copyright by Soukaina Maghfour, et al. This is an open access article distributed under the terms of the Creative Commons Attribution License, which permits unrestricted use, distribution, and reproduction in any medium, provided the original author and source are credited.

Source of Support: Nil, Conflict of Interest: None declared. 